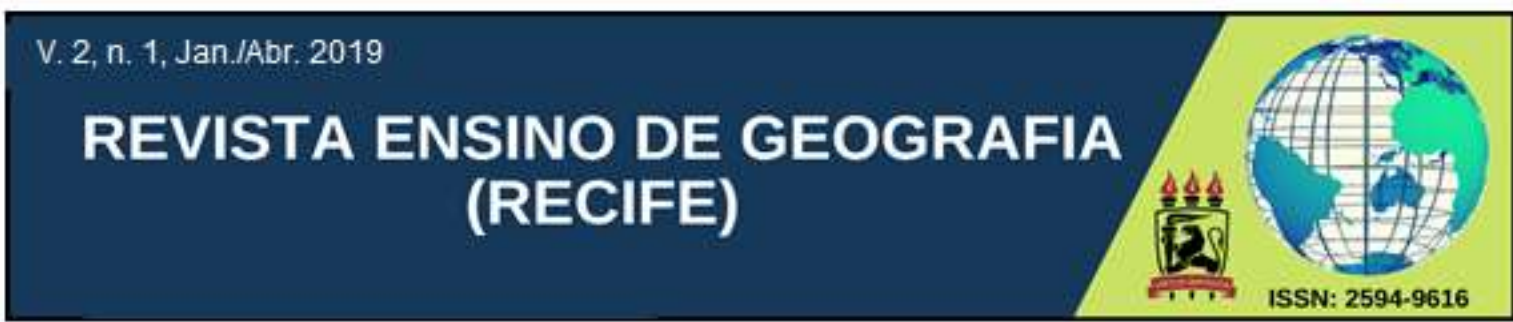

\title{
A AULA DE CAMPO NO ENSINO DA GEOGRAFIA: EXPERIÊNCIAS COTIDIANAS NA CIDADE PARA CONSTRUÇÃO DE APRENDIZAGENS
}

\author{
Myrian Cristina Santos de Jesus \\ Especialista em Ensino de Geografia (UESC) \\ myriancsdejesus@hotmail.com \\ ORCID iD: https://orcid.org/0000-0002-8476-5646 \\ Mateus Ferreira Santos \\ Doutorando do Programa de Pós-Graduação em Geografia (UFPE) \\ mateusfst@hotmail.com \\ ORCID iD: https://orcid.org/0000-0001-5099-3766
}

Artigo recebido em 28/06/2019 e aceito em 01/07/2019

\begin{abstract}
RESUMO: Este artigo apresenta contribuições a respeito da aula de campo no ensino básico da Geografia, além de apontar percursos metodológicos que podem ser adotados pelos professores da educação básica. É necessário perceber as mudanças que ocorrem na sociedade, tornando-se imprescindível para a compreensão e a construção do conhecimento espacial, além de favorecer o exercício da cidadania. O ensino de Geografia, enquanto conjunto de saberes que permitem a sociabilidade deve ser capaz de propor ao aluno o reconhecimento da cidade como palco de aprendizagens. A cidade e seus fenômenos precisam ter espaço na sala de aula, no intuito de conduzir o aluno a reconhecer-se como sujeito deste espaço, não de forma passiva, mas como cidadão e agente transformador. Para isso, foi feito uma pesquisa de cunho bibliográfico no intuito de dialogar com autores que discutem sobre o ensino de Geografia e a aula de campo, apresentando diferentes possibilidades metodológicas que podem ser utilizados por docentes da rede pública e privada, dispostos a promover aos seus alunos um ensino dinâmico, interativo e reflexivo, cuja teoria possa ser vivenciada durante a aula de campo.

Palavras-chave: Ensino de Geografia; Aula de Campo; procedimentos didáticos; cidadania.
\end{abstract}

\section{THE FIELD CLASS IN THE TEACHING OF GEOGRAPHY: DAILY LIFE EXPERIENCES IN THE CITY TO BUILD LEARNING}

\begin{abstract}
This article presents contributions about the field class in basic geography teaching, pointing out methodological paths that can be adopted by teachers of the city of basic education. It is necessary to understand the changes taking place in society, making it essential for understanding and building the spatial knowledge, and encourage the exercise of citizenship. The teaching of Geography, as a body of knowledge that allow sociability, should be able to propose to the student recognition of the city as a stage of learning. The city and its phenomena need to have space in the classroom, in order to drive the student to be recognized as the subject of this space, not passively, but as a citizen and transforming agent. For this, it made a bibliographic nature of research in order to dialogue with authors who discuss the teaching of geography and field class with different methodological possibilities that can be used by teachers of public and private, willing to promote their students a dynamic teaching, interactive and reflective, whose theory can be experienced during the field school.
\end{abstract}

Keywords: Geography teaching; Field class; didactic procedures; citizenship.

Jesus e Santos, 2019 


\section{INTRODUÇÃO}

A atual situação da educação, configurada pela desmotivação de alunos, precariedade de recursos e investimentos, falta de estrutura em algumas unidades escolares, bem como a desvalorização dos profissionais da educação são fatores que limitam e dificultam o ensino de qualidade. Além disso, a escola tem urgido por metodologias de ensino que se desloquem do campo teórico para o chão da sala de aula, respeitando as adversidades dos alunos e dos professores. Em um ambiente cheio de desafios como a escola, que se depara cotidianamente com as mudanças socioculturais e tecnológicas atuais, instigar os alunos e professores a romperem as fronteiras estruturais da escola representa um passo à frente para o ensino e aprendizagem. Perceber as mudanças nos diferentes espaços e lugares é imprescindível para a compreensão e construção dos saberes geográficos, sendo também um exercício de cidadania.

O espaço em que vivemos é cheio de representações e é de suma importância que o aluno tenha essa percepção; uma praça pode ter várias funções além da diversão, pode ser comércio, ponto de encontros, passagem de pedestres; como pode ter sido, em outro momento, testemunha de fatos históricos imprescindíveis para a construção e evolução da cidade (CAVALCANTI, 2012). O passado tem a função de explicar o futuro, bem como, os aspectos históricos são fundamentais para percebermos o presente e projetarmos esse futuro.

Partindo dessa ideia, o presente trabalho objetiva discutir o papel da aula de campo no ensino de Geografia como uma proposta metodológica para o estudo dos aspectos urbanos, para isso, o trabalho apoia-se em uma perspectiva crítica, que partirá do levantamento de aportes teórico-reflexivos que embasam a discussão da temática proposta.

Toda cidade preserva aspectos históricos e geográficos, não somente através de suas construções físicas, mas também pelo desenvolvimento socioeconômico, cultural e político, representados em sua paisagem. O estudo e o reconhecimento dessas particularidades podem contribuir para a formação de um novo olhar em seus habitantes. Assim, é fundamental que as novas gerações reconheçam esses aspectos históricos e geográficos não somente como meros repetidores, mas, exercendo seu dever de cidadãos, compreendendo o seu lugar e reafirmando sua identidade. 


\section{A AULA DE CAMPO NO ENSINO DA GEOGRAFIA: ARTICULAÇÕES POSSIVEIS}

A busca por metodologias significativas de ensino deve estar sempre presente no fazer pedagógico do professor de geografia. Oportunizar novas situações de aprendizagem para os alunos é fundamental para que novos sentidos e significados sejam criados, permitindo aos mesmos o desenvolvimento de diferentes percepções a respeito do conteúdo estudado, aproximando com as suas vivências. Estreitar os alunos ao estudo das transformações espaciais é fundamental para o entendimento da geografia do dia a dia. Tomita (1999, p. 13) destaca que "é importante que se estimule o educando a indagar o porquê das coisas para o mesmo não se conformar com a simples situação dos fatos, mas, partir para uma análise criteriosa com uma visão crítica".

Aula de campo desperta oportunidades, permite que o conhecimento escolar extrapolar os muros da escola e aproxime os educandos de realidades que na maioria das vezes não estão distantes. Também oportuniza professor e aluno a fazer pesquisa, entender as complexidades do espaço cotidiano, traçando paralelos com conteúdos trabalhados em sala, não só aqueles da disciplina geografia, mas de outras áreas do conhecimento.

É válido afirmar que fazer aula de campo não é fácil para o professor, tanto pela indisponibilidade de sair da escola com os seus educandos, extrapolando a carga horária proposta pela disciplina, quanto pelo árduo planejamento que deve se ter para que a aula não se torne uma mera excursão. No entanto, buscar meios para construir novas aprendizagens e dinamização do ensino, permitindo a criticidade dos alunos, é de grande valia, principalmente porque o ensino de qualidade tem acontecido em meio a desafios que a todo o momento vem sendo posto como superação. Segundo Bento (2014, p. 150),

[...] o ensino de Geografia tem por objetivo formar um raciocínio geográfico desde uma abordagem espacial, permitindo que os alunos construam modos de pensar a partir das lentes geográficas, lentes que têm a finalidade de promover o entendimento da produção do espaço pelo homem.

Pensar no ensino de geografia desvinculado das novas tendências atuais e não levando em consideração as relações do cotidiano dos alunos, que vai do micro para o macro, é um posicionamento errôneo, já que a construção do conhecimento deve ter um caráter dinâmico e multiescalar, sendo papel do professor oportunizar aos seus educandos meios para que eles enxerguem e entenda como se dá a organização do espaço geográfico. Nesse sentido, Citon e Shinobu (2013) apresenta que, 
A Geografia assume especialmente um caráter dinâmico, posto que o conhecimento geográfico mostra-se em constante transformação, demandando novas formas de ver, sentir e agir sobre o mundo. Nesta nova forma de conceber o ensino geográfico, o modelo de formação pautado somente na ideia de acúmulo de conhecimentos teóricos para posterior aplicação ao domínio da prática, não se mostra eficaz para entender a diversidade de alunos e a de situações-problemas que emergem na sala de aula (p. 122).

Desmitificar a ideia que o ensino de geografia se faz por meio de memorização e transcrição ainda não é fácil, já que existem professores que apresentam resistência para assimilar o novo, muitos ainda carregam sérios vícios de uma formação acadêmica propedêutica. Em consequência disso, temos alunos desmotivados, não detendo do saber geográfico essencial para o seu desenvolvimento como sujeito capaz de assumir um posicionamento político e crítico a respeito das tendências atuais.

Viveiro e Diniz (2009, p. 29) apresentam que a aula de campo permite o contato direto do estudante com o ambiente, possibilitando que ele interaja com situações reais, confrontando a teoria com a prática. Além de abordar conteúdos específicos, a metodologia aproxima o professor de seus alunos, permitindo que o processo de aprendizagem se dê de forma significativa e colaborativa, favorecendo que novos conceitos sejam criados e que experiências vividas sejam expostas.

Dentre vários sentidos e contextos a serem explorados em uma aula de campo, a paisagem é uma das categorias de análise indispensável para se trabalhar, pois revela as feições e transformações ocorridas no espaço que se faz com a interação da sociedade com a natureza. A paisagem revela mais que formas estáticas, ela possui movimento, cheiro e som (Santos 1998) que pode ser percebida pelos alunos e apontada pelo professor como um local indissociável das relações de poder, lutas de classe, movimento e afetividade, sendo representada por redes, territórios e lugares. A conexão dos diferentes conteúdos da geografia é fundamental para que os alunos consigam abstrair com mais precisão o que a paisagem tem a revelar, ou o que o professor quer trabalhar. Nessa direção,

[...] o trabalho de campo é um dos recursos que podem e devem ser utilizados no processo de leitura da paisagem, por ser o mesmo uma oportunidade de exercitar a atitude científica de investigar, entrevistar, examinar, observar, comprovar, estabelecer o elo entre o conhecimento teórico e empírico. Não é simplesmente contemplar o meio, é trazer a realidade para dentro da sala de aula. O aluno retorna enriquecido quando sai a campo para o estudo do meio, e tenderá a adotar a mesma atitude investigativa em outras oportunidades de observação (VEIGA; et al, 2010, p. 527). 
Mas para isso, é preciso ter bastante clareza que antes de qualquer aula de campo é necessário o conhecimento prévio do conteúdo e do espaço geográfico a ser estudado (SOUZA e CHIAPETTI, 2012). Também se deve fazer uma visita previa a área desejada, com o objetivo de esclarecer possíveis dúvidas que possam ocorrer no campo. Isso demonstra que a saída a campo não compreende só a saída da sala de aula, mas, o planejamento, a definição dos pontos a serem visitados, a execução e exploração dos resultados. Assim, entende-se que "limitar essa atividade apenas à visita constitui-se em um desperdício das potencialidades possíveis de serem trabalhadas por meio dessa modalidade didática" (VIVEIRO; et al, 2009, p. 30).

Diversos conteúdos da geografia podem ser trabalhados em aula de campo, seja de natureza teórica, prática, natural, social e contextos outros. Para isso, faz-se necessário um estudo detalhado por parte do professor para que tenha base teórica para fundamentar toda discussão com os alunos. Propor que os alunos realizem seu próprio campo é também uma grande oportunidade de reconhecerem diferentes espaços, fotografarem o que lhe chama mais atenção e no chão da sala de aula socializar tudo que foi visto/analisado, tirando as possíveis dúvidas com o professor. Essa metodologia de investigação pode aguçar nos alunos diferentes formas de reconhecer o seu lugar de vivência e apresentar questionamentos que podem ser respondidos por meio de pesquisas, análises e discussões com toda a turma. Nesse contexto, Souza e Chiapetti (2012, p. 9) destacam que a aula de campo "[...] proporcionaria a compreensão da realidade vivida pelos alunos e a apreensão de outros espaços geográficos externos ao seu cotidiano, ampliando as fontes de conhecimento que os levam à reflexão e à tomada de consciência sobre a organização do seu espaço geográfico".

É preciso deixar claro que a aula de campo só se torna eficaz a partir do momento que o aluno entende a organização do seu espaço e apresenta indicativos que compreendeu o conteúdo que lhe foi apresentado, além disso, se reconhece como sujeito modelador e determinante para as mudanças do seu lugar, aí sim, a aprendizagem significativa acontece. Há necessidade de todo um conjunto de ações promovidas pelo professor e o aluno, seja em sala de aula ou fora dos muros da escola, Casttelar (2011, p. 3) expõe que,

A ideia de aprendizagem significativa não está apenas focada em uma estratégia de aprender bem em um conjunto de atividades ou na relação direta com o cotidiano, mas entendo que ela acontece quando o aluno consegue se apropriar de um conhecimento, consegue compreender e ler o mundo em que vive, estabelecer significado no que está aprendendo, questiona, se interessa em aprender, se sente sujeito do seu processo de aprendizagem. 
Também, tais aprendizagens só acontecem quando o professor está preparado, seja com uma formação adequada ou quando ele se atualiza e busca novas formas de lidar com as realidades dos seus alunos e dos recursos disponibilizados pela escola. Sabemos que trabalhar no ensino básico com aula de campo em uma disciplina isolada não é fácil, até porque caminharemos contrário ao que é proposto pelos Parâmetros Curriculares Nacionais - PCN (1998) quando propõem um estudo interdisciplinar dos conteúdos e das disciplinas. Um dos entraves que sempre ocorre é a falta de tempo disponível para a realização do campo, já que na rede pública de ensino a carga horária da disciplina geografia para o ensino fundamental II é de 3 horas aula e do ensino médio, que não é mais disciplina obrigatória (BRASIL, 2017), de 2 horas aula. Dessa forma, urge a necessidade de parceria com outras disciplinas (BRAUN, 2005).

Outra limitação bastante comum sinalizada por muitos professores com relação a não fazer campo com os seus alunos no ensino de geografia é a falta de conhecimento do local em que os mesmos vivem, já que as descrições dos rios, morros, serras e do espaço urbano de muitos locais não estão presentes no livro didático. Braun (2005) revela que ensinar exige mais que transmissão de informações, exige pesquisa. Freire (1996 apud Braun 2005, p.73) salienta que,

\footnotetext{
A segurança com que a autoridade docente se move implica uma outra, a que se funda na sua competência profissional [...] ensinar exige pesquisa. Não há ensino sem pesquisa e pesquisa sem ensino [...] Pesquisa para constatar, constatando intervenho, intervindo, educo e me educo. Pesquiso para conhecer o que ainda não conheço e comunicar ou anunciar a novidade.
}

Portanto, limitações existem para a exceção de um trabalho de campo que forneça caminhos outros para uma aprendizagem significativa e colaborativa. Não que a aula de campo seja a única alternativa para isso, mas como propomos ao logo do trabalho, essa metodologia torna-se um caminho propositivo para extrapolar os limites físicos da escola e trabalhar com os cotidianos, as vivências, as percepções e principalmente com a troca de experiências que são expressas para além da sala de aula.

\section{CONHECENDO A CIDADE POR MEIO DA AULA DE CAMPO}

Possibilitar a aproximação do aluno com situações reais implica em uma maior capacidade de apreensão e apropriação do espaço geográfico; essa apropriação pode se dar de várias maneiras. Nesse âmbito, a aula de campo tem um papel significante como instrumento 
fundamental para o estudo e o reconhecimento de vários lugares que já fazem parte do cotidiano dos alunos, mas que não são compreendidos com um espaço que está em constante transformação, carregado de muitos significados que só com um conhecimento prévio da geografia podem ser percebidos. Souza e Chiapetti (2012) apresenta que o trabalho de campo constitui uma metodologia que engloba a observação, a análise e a interpretação de fenômenos no local e nas condições onde eles ocorrem naturalmente.

Assim, entender a organização da cidade, seus equipamentos e as diferentes funcionalidades que o espaço urbano apresenta é muito importante para o professor e aluno, já que os diversos espaços públicos pertencem aos mesmos, pois eles são sujeitos sociais na/da cidade. O espaço urbano é substrato da reprodução social, é nele que a população urbana vive, se apropria, explora e dá diferentes significados. Daí a necessidade de reconhecimento por parte dos alunos desse espaço, pois,

\footnotetext{
Em função da dinâmica urbana atual, na qual a cidade se torna palco de transformações e movimentos decorrentes do sistema capitalista de produção, torna-se de suma importância na Geografia (escolar) o estudo da cidade e do espaço urbano; bem como dos processos e fenômenos que neles ocorrem, a fim de que o sujeito que habita esses espaços, aproprie-se desse conhecimento para melhor atuar em seu cotidiano (PEREIRA; PAULA, 2010, p. 1).
}

Na tentativa de melhor compreender diferentes características presentes na cidade é ideal que o professor faça alguns questionamentos ao planejar a ida com os seus alunos para o campo, como: Quando surgiu essa cidade que iremos estudar? Qual a importância dessa praça para a vizinhança que está ao seu redor? Para os que ali trabalham? Para os que por ali passam diariamente? Que tipo de serviços a cidade oferece? Quais transformações ela vem apresentando ao longo dos últimos anos? Quantos habitantes ela tem? Como é a distribuição da população nos diferentes bairros? Esses e outros questionamentos devem ser levantados e respondidos para que o professor conheça ainda mais o que será estudado e apresente aos alunos maiores riquezas de detalhes. Bento (2014, p. 144) salienta que "vivemos uma condição de profundo processo de urbanização, e que cada vez mais as cidades se tornam locais complexos e objetos de estudo para o ensino de geografia".

Levando em consideração a ideia de Bento (2014), reconhecemos que a cidade sempre está em processo de construção, modificação e recriação, sendo necessário enxergá-la em sua totalidade, percebendo os aspectos internos e externos que a envolvem, pois o homem é o seu principal agente modelador. Fazer dessa conjuntura de espaços um laboratório de investigação ao ar livre é muito enriquecedor na educação, principalmente por trabalhar com a vivência de várias pessoas que ali desenvolvem as suas atividades, residem, se divertem, e sobre isso 
aplicar valor. Mas não podemos deixar de destacar que essa mesma cidade pode ser percebida de diferentes maneiras, daí a necessidade de um trabalho adequado com os alunos, deixando que eles se posicionem frente ao que é visto e percebido.

Levar em conta o olhar aguçado dos alunos no processo de ensino e aprendizagem é fundamental, pois cada olhar traduz aspectos que jamais podem ser percebidos por uma só pessoa. A troca de informações e de interações que ocorrem em uma aula de campo pode ser bem mais proveitosa que todo o aparato técnico apresentado pelo professor em sala de aula. É preciso dar voz aos educandos, reconhecendo as suas potencialidades para a construção coletiva de um conhecimento participativo e geográfico.

Nessa direção, abaixo apresentaremos caminhos propositivos para a execução de aula de campo, reconhecendo que no processo de aprendizagem, especificamente realizado pela escola, existem caminhos alternativos para se construir conhecimento. Alguns podem ser bem desempenhados, mas obter resultados não satisfatórios, outros com um adequado planejamento têm a possibilidade de aproximar o educando de um conhecimento que não está tão longe de sua vivência, mas que ainda não é enxergado, sendo esse é o papel da aula de campo.

\subsection{Percursos metodológicos para execução de aula de campo}

Partindo dessa ideia, o presente tópico apresenta alguns contributos que podem colaborar com o professor para a preparação de uma aula de campo a ser executada na cidade que os alunos residem, ou outras, mas para isso, é necessário deixar claro que existem caminhos necessários a serem percorridos. Como já foi apresentado no decorrer do trabalho, para propor uma aula/trabalho de campo é necessário bastante planejamento, tanto pelo professor individualmente, quanto com todo o público que vai executar, acordando principalmente as possibilidades e impossibilidades que serão encontradas em campo.

Assim, para uma boa execução dessa atividade é necessário a adoção de três etapas fundamentais: o pré-campo, o campo e o pós campo. O pré-campo é a primeira fase a ser pensada, pois é o momento de traçar os objetivos; adotar uma metodologia para abordagem dos conteúdos; pedir autorização aos pais ou responsáveis pelos alunos, como também aos locais que serão frequentadas; separar os materiais que serão utilizados; verificar quais as condições desses locais; fazer um levantamento do melhor trajeto para que não haja ocorrências de transtornos, e refletir as contribuições que a saída da escola pode apresentar para os alunos que irão participar. Dessa forma, Silva et al (2010) apresenta que, 
O pré-campo é fundamental para que o aluno acompanhe a trajetória a ser estudada e questione com curiosidade, sem repetir simplesmente aquela famosa frase que costuma ressaltar a cada parada: “O que é que eu estou fazendo aqui?”. O pré-campo vai nortear o aluno como uma representação da realidade. Quando estiver na aula de campo a sua mente já estará aberta às reflexões teórico-práticas que fundamentarão a pesquisa (p. 190-191)

A importância do planejamento para se realizar uma aula de campo se faz necessário para que o estudo não se tornar um passeio turístico. Mesmo fora da sala de aula, o professor deve agir como tal e os alunos como tais. O cuidado com os trajes deve existir para evitar acidentes e outras eventos, afinal, a turma estará em aula.

A segundo etapa da metodologia aqui apresentada consiste no campo, a efetivação da atividade pelo professor e os alunos. Nesse sentido Sternberg (1946 apud NEVES, 2010, p. 33) levanta algumas formas de coletar informações no campo. São elas: “observação; registro; inquérito geográfico e entrevista; coleção e preparação de amostras; terminação do trabalho de campo e reconhecimento geográfico e avião". Esses e outros fatores são condicionantes para que tudo que foi trabalhado em sala e planejado seja verificado e validado na prática, visto que, os conhecimentos necessários já foram tralhados e nesse momento o objeto proposto para estudo só estará sendo esmiuçado, verificado, analisado, propiciando que o aluno tenha maiores contatos com o espaço vivido e entenda como esse espaço está organizado, seja pelas estruturas físicas ou pelas relações socais que ocorrem.

Oliveira e Souza (2009) apresentam que o campo é uma oportunidade de despertar os alunos da passividade, que o ensino-aprendizagem mais simplista tende a conduzir. Salienta ainda que,

\begin{abstract}
Essa compreensão favorece o reconhecimento da aula em campo como instrumento de acesso ao binômio espaço/espacialidade, cujo movimento carrega, ao estudante, potenciais pedagógicos de facilitadores da elucidação do mundo pela geografia. Não se trata de uma substituição da sala pela 'rua', mas uma ligação do que é produto/produzido pelo aluno - nas diversas escalas do particular - com o processo de mundialização que o orienta à condição de agir no espaço de diferentes maneiras, ajudando a construir a amplitude da aula, de tal modo a fazê-lo sentir e (re)agir sobre o seu próprio produto e além dele (OLIVEIRA e SOUZA, 2009, p. 199).
\end{abstract}

Nessa perspectiva, a aula de campo deve ser provocativa, oportunizando os alunos a novas a investigações. É necessário chamar atenção, que essa etapa (a efetivação do campo), não é mais ou menos importante que as outras, ela deve estar sincronizada com as outras, visto que, as atividades não se findam com o retorno à sala de aula, pois posterior ao campo 
deve haver um reinicio de todo o processo de aprendizagem, que abordamos aqui como póscampo.

O pós-campo consiste no retorno a sala de aula, momento em que todas as experiências, impressões, dúvidas e sugestões devem ser socializadas, tanto pelos alunos quanto pelo professor. Os registros, como imagens, anotações, vídeos, entrevistas (...), podem ser solicitadas pelo professor para uma breve exposição, ou serem cobradas em forma de relatório de campo. Oliveira e Souza (2009, p. 204) caracterizam que, “[...] a atividade de retorno à sala de aula completa aquilo que no campo escapou, ficou subentendido ou malentendido. [...] Não se esgota com a simples 'avaliação', na qual uma turma afirma ter sido ótimo 'ver' a 'realidade"'.

Portanto, por meio dessas etapas o trabalho de campo apresenta maior legitimidade no núcleo escolar, destacando mais uma vez que essa proposta apresenta uma dimensão bastante significativa no processo de ensino e aprendizagem. É preciso apontar que essa metodologia não se resume apenas ao que foi anunciada, ela deve compreender experiências cotidianas dos participantes para que não se torne uma receita pronta e acabada.

\section{CONSIDERAÇÕES INCONCLUSIVAS}

Conceber a aula de campo como uma metodologia que vai sanar as dificuldades que a escola enfrenta, como ensino decorativo, falta de infraestrutura e por vezes métodos obsoletos, não é verdade; esta, se bem planejada e empregada, tem a possibilidade de aproximar os alunos de diferentes realidades, demostrando as alterações que ocorrem em seu cotidiano e que não são percebidas, além disso, essa forma de trabalho tem contribuído para que o conhecimento não se limite aos muros da escola, motivando os alunos para novas descobertas e experiências, contribuindo para uma aprendizagem coletiva.

Perceber as transformações que ocorrem nos espaços urbanos é de fundamental importância, principalmente porque a cidade com seus equipamentos é fruto de ações e modificações da sociedade; os alunos estão inseridos nessa rede urbana que sofre mudanças constantemente, eles também são agentes modeladores da cidade e por vezes, contribuem para que determinados locais tenham características singulares.

O espaço urbano pode se tornar uma sala de aula a céu aberto, se as peculiaridades do local forem inseridas como caminhos para se entender como um município se organiza e como ele vem se desenvolvendo desde a municipalização até a fase atual. Nessa perspectiva, 
o intuito desse trabalho é despertar no professor de geografia quais os mecanismos necessários para se adotar a aula de campo como uma metodologia que mais se aproxima dos diferentes contextos dos alunos, demostrando que essa proposta ainda deve ser muito discutida e que cada professor deve utilizar de estratégias específicas para o preparo de suas aulas.

Portanto, percebe-se o quanto é importante introduzir a aula de campo nas aulas de geografia, sem deixar passar despercebidos os conhecimentos do senso comum dos alunos que tanto podem enriquecer a prática pedagógica do professor. O conhecimento não deve de forma alguma ser construído de forma isolada, distante dos agentes que irão se apropriar dos saberes para uma possível transformação social.

\section{REFERÊNCIAS}

BRASIL. Secretaria de Educação Fundamental. Parâmetros curriculares nacionais: geografia / Secretaria de Educação Fundamental. Brasília: MEC/ SEF, 1998.

BRASIL, Lei no 13.415/2017 de Diretrizes e Bases da Educação Nacional. Ministério da Educação. Brasília: MEC, 2017.

BENTO, I. P. Ensinar e Aprender Geografia: pautas contemporâneas em debate. Revista Brasileira de Educação Geográfica, Campinas, V. 4, n.7, p.143-157, jan/jun., 2014.

BRAUN, A. M. S. Rompendo os Muros da Sala de aula: O trabalho de campo como uma linguagem no Ensino de Geografia. 2005. Dissertação (Mestrado) - Universidade Federal do Rio Grande do Sul. Porto Alegre - RS, 2005. Disponível em<https://www.lume.ufrgs.br/bitstream/handle/10183/6901/000492074.pdf?sequence=1>. Acessado em 02 de abril de 2019.

CASTELLAR, S. M. V. A Superação dos limites para uma educação geográfica significativa: um estudo sobre a e na cidade. Revista Geográfica de América Central, Número Especial EGAL, Costa Rica, II Semestre, 2011, p. 1-25.

CAVALCANTI, L. de S. A geografia escolar e a cidade: Ensaios sobre o ensino de geografia para a vida urbana cotidiana. Campinas, SP: Papirus, 2012.

CITON, R. C.; SHINOBU, P. F.P. Aula de campo como espaço de construção do saber geográfico. Revista Eletrônica Pro-Docência/UEL. Edição nº 5, vol. 1, jun./dez., 2013.

FREIRE, P. Observação Registro Reflexão - Instrumentos metodológicos - Séries

Seminários. São Paulo: PND - produções gráficas, 1996. 
OLIVEIRA, C. D. M.; SOUZA, R. J. S. A. As travessias da aula de campo na geografia escolar: a necessidade convertida para além da fábula. Educação e Pesquisa, São Paulo, v. 35, n.1, p. 195-209, jan./abr. 2009.

PEREIRA, Z. R; PAULA, F. M. de Assis. Contribuições e possibilidades para o ensino de geografia: a cidade e espaço urbano como pressupostos da cidadania. Porto Alegre, AGB EGAL, 2010.

SANTOS, Milton. Metamorfose do espaço habitado: Fundamentos Teórico e Metodológico da Geografia. Hucitec. São Paulo 1988.

SILVA, J. S. R.; SILVA, M. B.; VAREJÃO, J. L. Os (des)caminhos da educação: a importância do trabalho de campo na geografia. VÉRTICES, Campos dos Goytacazes/RJ, v. 12, n. 3, p. 187-197, set./dez. 2010.

SOUZA, S. O.; CHIAPETTI, R. J. N. O Trabalho de Campo como estratégia ao ensino de Geografia. Revista de Ensino de Geografia, v. 3, p. 3-22, 2012.

TOMITA, L. M. S. Trabalho de campo como instrumento de ensino em Geografia. Geografia (Londrina). V. 8, N. 1, Jan-Jun, Londrina, 1999, p. 13-15.

VEIGA, L. A.; SILVA, A. L.; ALIEVI, A. A. Ensino e Geografia: trabalho de campo e análise da paisagem. II Simpósio Paranaense de Estudos Climáticos e XIX Semana de Geografia. Maringá, 20 a 24 de Setembro de 2010.

VIVEIRO, A. A.; DINIZ, R.E.S. As atividades de campo no ensino de ciências: reflexões a partir das perspectivas de um grupo de professores. In: NARDI, R. Ensino de ciências e matemática, I: temas sobre a formação de professores. São Paulo: Editora UNESP; São Paulo: Cultura Acadêmica, 2009. 